\title{
ПРОГНОЗИРОВАНИЕ ИНФЛЯЦИИ В ХОДЕ УПРАВЛЕНИЯ ИНВЕСТИЦИОННОЙ БЕЗОПАСНОСТЬЮ РОССИИ
}

\section{(c) 2019 Зубова Юлия Анатольевна}

кандидат экономических наук, старший преподаватель кафедры гуманитарных и социальных наук

Саратовский военный ордена Жукова Краснознаменный институт войск национальной гвардии Российской Федерации, Россия, Саратов

E-mail: osier703@yandex.ru

Предложена методика краткосрочного прогнозирования инфляции с использованием метода бинарной логистической регрессии, обоснована целесообразность применения этой методики в управлении инвестиционной безопасностью государства. Данная методика позволяет получить ответ на вопрос о том, превысит ли инфляция заранее установленное пороговое значение, а также получить оценку вероятности наступления указанного события.

Ключевые слова: инвестиционная безопасность, инфляция, прогноз, бинарная логистическая регрессия.

Под инвестиционной безопасностью России в настоящей статье понимается такое состояние ее экономики, в котором ее обеспеченность средствами производства находится на уровне, сопоставимом с тем, что достигли страны-лидеры мировой экономики. Достижение этого уровня является необходимым условием экономического суверенитета нашей страны. Если мы будем уступать развитым странам в обеспеченности современными высокотехнологичными средствами производства, мы не сможем защитить свой внутренний рынок от экспансии зарубежных товаропроизводителей, не сможем успешно конкурировать с ними на внешнем рынке и неизбежно окажемся на периферии мирового экономического развития.

Управлению инвестиционной безопасностью государства посвящено немало научных работ, например, работы Н.М. Захватовой [1], Д.А. Литвинова и Р.В. Бузина [2], С. Нарышкина [3], Е.А. Мамий и В.М. Лембуровой [4], а также других авторов. В одной из этих работ предлагается так называемая колебательная модель обеспечения инвестиционной безопасности [5]. Согласно этой модели основными мерами достижения инвестиционной безопасности в нашей стране должны стать меры стимулирующей фискальной и мягкой монетарной политики. Действительно, нет иного способа добиться коренного технического перевооружения отраслей и комплексов национального хозяйства, кроме:

- наращивания государственных расходов, например, расходов на софинансирование ре- альных инвестиционных проектов, на предоставление госгарантий по долгосрочным кредитам, на субсидирование процентных ставок по этим кредитам и т.п.;

- уменьшения налоговой нагрузки на нефинансовые корпорации и расширения за счет этого их собственных возможностей по наращиванию и совершенствованию своей материально-технической базы;

- расширения денежного предложения и снижения за счет этого процентных ставок по кредитам, необходимым предприятиям для приобретения нового оборудования и освоения передовых технологий.

Однако применение мер стимулирующей фискальной и мягкой монетарной политики на протяжении достаточно продолжительного периода времени приводит, как правило, к скачкообразному росту цен. Для предотвращения таких ценовых скачков не остается ничего иного, кроме применения мер сдерживающей фискальной и жесткой монетарной политики, например, сокращения госрасходов и денежного предложения.

Но применение этих мер тоже не может продолжаться неопределенно долго. В долгосрочной перспективе указанные меры подавляют инвестиционную активность хозяйствующих субъектов, замедляют кругооборот капитала, ведут к техническому застою. Рано или поздно возникает необходимость в смягчении финансовой и денежно-кредитной политики.

Таким образом, необходимо чередование 
мер стимулирующей и сдерживающей фискальной политики, а также мягкой и жесткой монетарной политики (что и предлагается в рамках колебательной модели обеспечения инвестиционной безопасности).

Смену курса налогово-бюджетного и денежно-кредитного регулирования предлагается производить:

- в момент опасного приближения к ценовому скачку (в случае изменения стимулирующей фискальной политики на сдерживающую и мягкой монетарной политики - на жесткую);

- в момент достаточного удаления от возможного ценового скачка (в противном случае).

В предложенной модели, однако, нерешенным остался вопрос о том, как предсказывать ценовые скачки. Восполнению этого пробела и будет посвящена настоящая работа.

Итак, прогнозирование инфляции в целях управления инвестиционной безопасностью в рамках колебательной модели сводится к предсказанию ценовых скачков, то есть к предсказанию наступления одного из двух взаимоисключающих событий: «ценовой скачок произойдет» и «ценовой скачок не произойдет».

Для решения подобной задачи был выбран метод бинарной логистической регрессии. Данный метод позволяет предсказывать значение дихотомической переменной по значениям независимых переменных, а также определять вероятность того, что дихотомическая переменная примет одно из двух своих возможных значений:

$$
p=\frac{1}{1+e^{-z}},
$$

где

$p$ - вероятность наступления события, которому соответствует большее значение зависимой дихотомической переменной;

$z$ - значение функции логистической регрессии вида:

$$
z=b_{0}+b_{1} x_{1}+b_{2} x_{2}+\ldots+b_{n} x_{n},
$$

где

$b_{0}$ - константа;

$b_{1}, b_{2}, \ldots, b_{n}-$ коэффициенты логистической регрессии;

$x_{1}, x_{2}, \ldots, x_{n}-$ независимые переменные.

Если $p<0,5$, то с вероятностью $1-p$ наступит событие, которому соответствует меньшее зна- чение зависимой дихотомической переменной.

Если $p \geqslant 0,5$, то с вероятностью $p$ наступит событие, которому соответствует большее значение зависимой дихотомической переменной.

Все расчеты производились в статистическом пакете SPSS Statistics.

В качестве зависимой переменной был выбран месячный прирост индекса потребительских цен (IPC), в качестве предикторов - месячные приросты индексов промышленного производства $(I P)$, цен на бензин $(G)$, номинальной начисленной заработной платы $(w)$, денежной массы $(M)$, курса доллара по отношению к рублю $(D)$, средневзвешенных процентных ставок по кредитам, предоставленным кредитными организациями физическим лицам и нефинансовым организациям в рублях (RKD, $R K C)$, средневзвешенных процентных ставок по привлеченным кредитными организациями вкладам (депозитам) физических лиц и нефинансовых организаций в рублях $(R D D, R D C)$, а также предыдущие значения прироста индекса потребительских цен (IPC_Avto). Все исходные данные были взяты за период 2011-2018 гг.

Поскольку в рядах указанных данных прослеживались выраженные сезонные колебания, все они были подвергнуты десезонализации методом экспоненциального сглаживания.

Зависимая переменная была дихотомизирована пороговым методом: тем уровням ряда, которые превысили допустимый порог, были присвоены значения «1», остальным - «0». Величина порога обычно устанавливается субъектом прогнозирования и определяется целями разработки прогноза. В настоящей работе в качестве порога прироста индекса потребительских цен выбрано значение 6\% годовых или 0,5\% в месяц:

$$
\sqrt[12]{\frac{6+100}{100}} 100-100=0,5
$$

Таким образом, в анализируемом ряду динамики оказалось 53 уровня со значением «1»: январь - июль 2011 г., июнь - октябрь 2012 г., декабрь 2012 г.- август 2013 г., январь 2014 г.август 2016 г. Остальные 43 уровня получили значение «0» (рисунок 1$)$.

При построении логистической регрессионной модели $z=b_{0}+b_{1} I P+b_{2} G+b_{3} w+b_{4} M+b_{5} D+$ $b_{6} R K D+b_{7} R K C+b_{8} R D D+b_{9} R D C+b_{10}$ AvtoIPC в качестве допущения было принято, что зависимая переменная реагирует на изменения пре- 


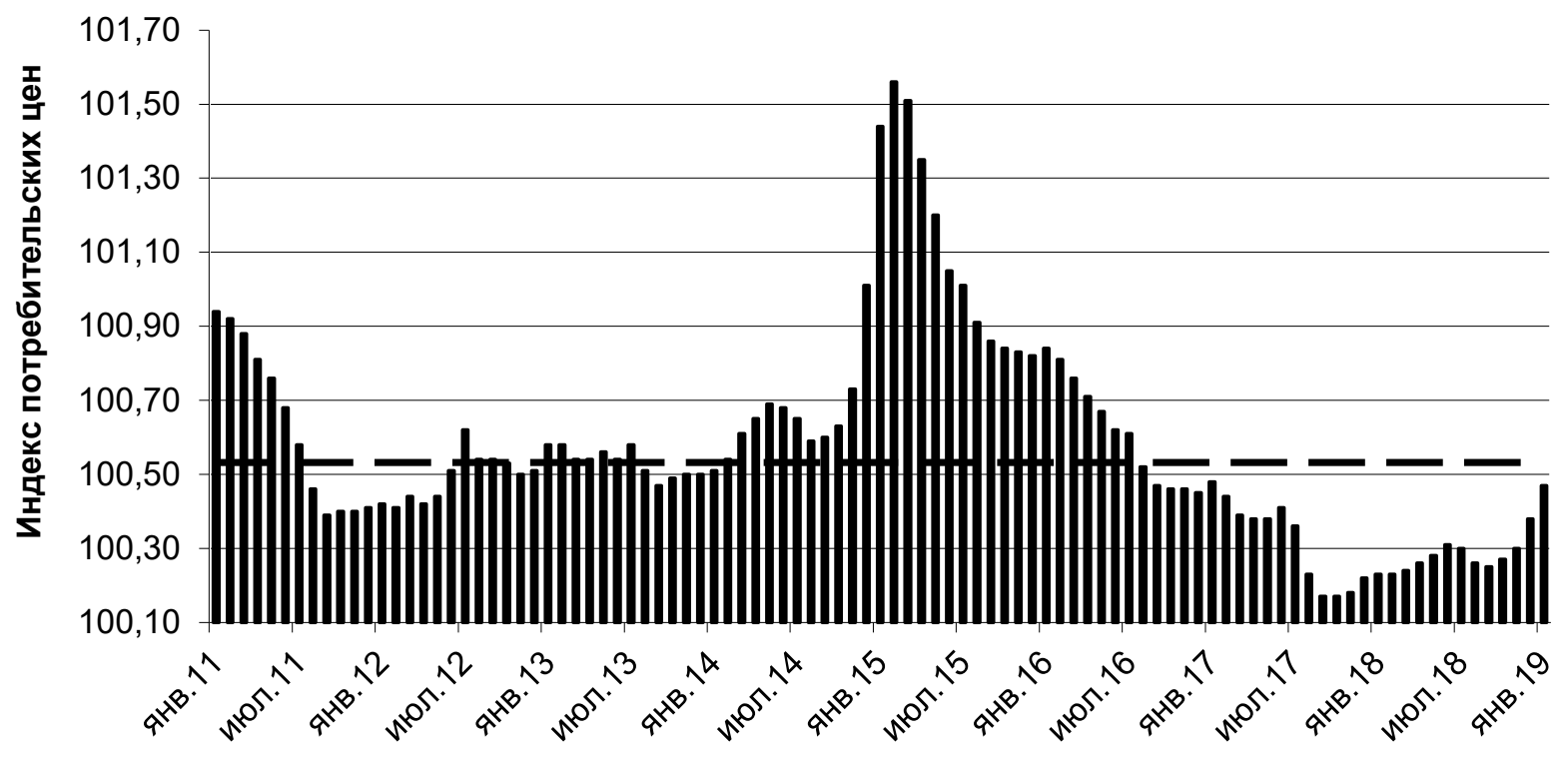

Puc. 1. Динамика индекса потребительских цен

Таблица 1. Качественные характеристики моделей $z$ с различным временным лагом

\begin{tabular}{|c|c|c|c|c|c|c|}
\hline & \multicolumn{6}{|c|}{ Модель } \\
\hline & 1 & 2 & 3 & 4 & 5 & 6 \\
\hline Лаг & 1 мес. & 2 мес. & 3 мес. & 4 мес. & 5 мес. & 6 мес. \\
\hline Процент верных предсказаний, всего & 95,7 & 89,1 & 95,6 & 94,4 & 92,1 & 89,8 \\
\hline $\begin{array}{l}\text { Процент верно предсказанных нулевых } \\
\text { уровней ряда (отсутствия ценовых скачков) }\end{array}$ & 90,7 & 86,0 & 95,3 & 93,0 & 90,7 & 85,7 \\
\hline $\begin{array}{l}\text { Процент верно предсказанных единичных } \\
\text { уровней ряда (ценовых скачков) }\end{array}$ & 94,0 & 91,8 & 95,8 & 95,7 & 93,5 & 93,5 \\
\hline $\begin{array}{l}\text { Количество ложноположительных предска- } \\
\text { заний (ценовой скачок был предсказан, но в } \\
\text { действительности не произошел) }\end{array}$ & 2 & 6 & 2 & 3 & 4 & 6 \\
\hline $\begin{array}{l}\text { Количество ложноотрицательных предска- } \\
\text { заний (ценовой скачок не был предсказан, } \\
\text { но в действительности произошел) }\end{array}$ & 2 & 4 & 2 & 2 & 3 & 3 \\
\hline -2Log правдоподобие & 20,095 & 37,806 & 24,572 & 29,904 & 36,402 & 44,990 \\
\hline $\mathrm{R}^{2}$ квадрат Нейджелкерка & 0,919 & 0,830 & 0,896 & 0,868 & 0,831 & 0,777 \\
\hline$\chi^{2}$ модели & 108,303 & 89,342 & 101,305 & 94,685 & 86,877 & 76,822 \\
\hline Значимость модели & 0,000 & 0,000 & 0,000 & 0,000 & 0,000 & 0,000 \\
\hline
\end{tabular}

дикторов с некоторым временным лагом. Поскольку точная величина этого лага не известна, было решено построить несколько моделей с разными лагами и выбрать из них ту, что имеет наилучшие качественные характеристики (табл. 1).

Как видим, лучшими качественными характеристиками обладают модели с месячным и трехмесячным лагом. Они дают самый высокий процент верных предсказаний (95,7 и 95,6\% соответственно) и самое минимальное число ошибочных предсказаний (4 против 5-10 в других моделях). Также модель с месячным лагом объ- ясняет 91,9\% дисперсии зависимой переменной, а модель с трехмесячным лагом - 89,6\% (это больше, чем какая-либо другая модель). Кроме того, указанные модели имеют самое высокое значение $\chi^{2}$ и самое низкое значение отрицательного двойного логарифма функции правдоподобия.

Однако с практической точки зрения больший интерес представляет модель с трехмесячным лагом, поскольку она дает больший период упреждения и, соответственно, больше времени для проведения мероприятий по предотвращению предсказанного ею ценового скачка. 
Для построения данной модели был использован один из пошаговых методов включения переменных, а именно метод отношения правдоподобия. Поэтому в нее были включены не все предикторы, но только значимые на уровне $5 \%$ :

$z=4,199-2,742 M-12,506 I P+1,118 R K C+$ 2,381AvtoIPC.

Произведем по данной модели расчет вероятности наступления ценового скачка в январе 2019 г. Для этого подставим в нее значения $M, I P$, RKC, AvtoIPC за октябрь 2018 г., то есть значения, наблюдаемые тремя месяцами ранее прогнозируемого события. Получим:

$$
z=-7,55 \text {. }
$$

Тогда вероятность наступления ценового скачка в январе 2019 г.:

$$
p(1)=\frac{1}{1+e^{7,55}}=0,001
$$

Таким образом, модель предсказывает отсутствие ценового скачка, то есть наступление события, которому соответствует меньшее значение зависимой дихотомической переменной. Вероятность наступления этого события составляет:

$$
p(0)=1-0,001=0,999
$$

Данный прогноз подтвердился на практике: десезонализированная величина индекса потребительских цен в январе 2019 г. составила $100,47 \%$.

Итак, метод бинарной логистической регрессии показал свою пригодность для краткосрочного прогнозирования инфляции. Разработанная на его основе методика предсказания ценовых скачков существенно улучшает колебательную модель обеспечения инвестиционной безопасности государства, делает ее практически осуществимой.

\section{Библиографический список}

1. Захватова Н.М. Инвестиционная безопасность как составляющая системы экономической безопасности региона: дис. на соиск. учен. степ. канд. экон. наук: 08.00.05 / Московская академия экономики и права. М. 2010. 156 c.

2. Литвинов Д.А., Бузин Р.В. Теоретические основы инвестиционной безопасности национальной экономики // Научные ведомости Белгородского государственного университета. Серия: История. Политология. Экономика. Информатика. 2008. Т. 10. № 8. С. 187-192.

3. Нарышкин С. Инвестиционная безопасность как фактор устойчивого экономического развития // Вопросы экономики. 2010. № 5. С. 22.

4. Мамий Е.А., Лембурова В.М. Инвестиционная безопасность в системе экономической безопасности государства // Новая наука: опыт, традиции, новации. 2016. № 4-1. С. 113-117.

5. Шеховцова Ю.А. Стратегия обеспечения инвестиционной безопасности России: теория и методология. Москва. 2017. С. 54, 275. 